\title{
Large Population Screening Identified the Main Risk Factors of Stroke in Shashi District of Jingzhou City
}

\author{
Panpan Zheng1, Ling Zhang2*, Rui Sun ${ }^{1}$, Xiaoyan Peng2 \\ ${ }^{1}$ Department of Medicine, Yangtze University, Jingzhou, China \\ ${ }^{2}$ Nursing Department of First Affiliated Hospital of Yangtze University, Jingzhou, China \\ Email: ^317050697@qq.com
}

How to cite this paper: Zheng, P.P., Zhang, L., Sun, R. and Peng, X.Y. (2020) Large Population Screening Identified the Main Risk Factors of Stroke in Shashi District of Jingzhou City. Yangtze Medicine, 4, 70-78.

https://doi.org/10.4236/ym.2020.41007

Received: July 8, 2019

Accepted: March 27, 2020

Published: March 30, 2020

Copyright $\odot 2020$ by author(s) and Scientific Research Publishing Inc. This work is licensed under the Creative Commons Attribution International License (CC BY 4.0).

http://creativecommons.org/licenses/by/4.0/

\begin{abstract}
Objective: This paper aims to screen and analyze the current status of high-risk stroke patients in Shashi District of Jingzhou City and the exposure levels of related risk factors, and provides suggestions as the references for prevention and treatment of stroke. Methods: Using cluster sampling, on-site investigations were conducted on 1060 permanent residents aged 40 years and over at 3 townships and 2 communities in Shashi District of Jingzhou City from January 2018 to December 2018. Risk assessment of stroke is based on the stroke risk screening form. Statistical analysis was performed by using SPSS 22.0 software. Results: After making a stroke risk assessment, a total of 313 high-risk stroke patients were screened, and the detection rate was 29.53\%. The exposure rate of risk factors from high to low was hypertension (70.93\%), dyslipidemia (46.33\%), less physical exercise (46.01\%), diabetes (36.10\%), overweight (33.55\%), smoking (33.23\%), family history of stroke (24.92\%), atrial fibrillation or valvular heart disease $(7.35 \%)$. There are statistically significant differences among all risk factors between the high-risk group and middle and low-risk groups $(P<0.05)$. There is a statistically significant difference in smoking between men and women $(P<0.05)$. Conclusion: The detection rate of high-risk stroke patients in Shashi District of Jingzhou City is high. Hypertension, dyslipidemia and less physical exercise are the main risk factors of stroke occurrence and recurrence in the region. The prevention and treatment of risk factors for stroke should be strengthened to control the incidence and recurrence rate of stroke.
\end{abstract}

\section{Keywords}

Stroke, High-Risk Population, Screening, Risk Factors 


\section{Introduction}

Stroke is a neurological disease of cerebral blood circulation disorder caused by a combination of various factors, with high morbidity, high disability and high recurrence rate and is one of the major causes of disability and death worldwide [1]. Especially in recent years, the incidence of stroke in China has increased by $8.7 \%$ per year, and the mortality rate is 4 to 5 times that of developed countries in Europe and America [2]. With the aging and urbanization process accelerating, residents' unhealthy lifestyles are prevalent, and the incidence of strokes has risen sharply. It is speculated that the incidence of cerebrovascular disease in China will increase by about $50 \%$ in 2030 compared with 2010 . The per capita cost of hospitalization for cerebral hemorrhage and cerebral infarction in China increased by $61.4 \%$ and $31.4 \%$ respectively compared with 2010 , which brought heavy economic burden to families and society [3] [4]. Therefore, the prevention and treatment of stroke are extremely urgent.

The prevention and treatment of stroke began in the United States as early as 1950, and the American stroke mortality rate dropped by 34.8\% between 1972 and 1985 [5]. The project has been carried out in Japan, Australia, Canada, New Zealand and other countries, and has achieved remarkable results, resulting in a significant reduction in stroke morbidity and mortality [6] [7] [8] [9]. At present, China has launched a stroke screening and prevention program in some cities. According to relevant research reported, the proportion of high-risk groups is between $13.45 \%$ - $21.30 \%$ [10] [11] [12] [13]. About 1.6 million people died from stroke each year in China, which has become the primary cause of death among Chinese residents [14]. It shows that the burden of stroke in China is serious, and the prevention and treatment of stroke are extremely urgent. Studies have shown that among the risk factors that cause stroke, in addition to gender, age and genetic factors, the rest are closely related to people's daily habits and behaviors, and can be controlled by changing bad lifestyles and behaviors. Approximately $94 \%$ of stroke patients are caused by controlled risk factors, and early screening for risk factors and standardized treatment of stroke patients can effectively reduce stroke morbidity, recurrence rate, morbidity and mortality [15] [16].

This paper aims to screen and analyze the current status of high-risk stroke patients in Shashi District of Jingzhou City and the exposure levels of related risk factors, and provides suggestions as the references for prevention and treatment of stroke. The screening results are now reported as below.

\section{Materials and Methods}

\subsection{Research Object}

According to the screening standards of the National Health and Family Planning Commission's Stroke Screening and Prevention Engineering Committee, a cluster sampling method was adopted to screen the permanent residents of the three townships and two communities in Shashi District of Jingzhou City, aged 
40 and above. A total of 1060 people were screened. Inclusion criteria: 1) The permanent residents who aged 40 and above in Shashi District of Jingzhou City; 2) A history of stroke or TIA, or patients with the following $\geq 3$ risk factors: hypertension, hyperlipidemia, diabetes, atrial fibrillation or valvular heart disease, smoking, lack of exercise, overweight, family history of stroke. 3) Volunteer to participate in this study. Exclusion criteria: 1) Newly born stroke patients less than 6 months; 2) Patients who cannot be screened for severe physical illness; 3) Patients who are unable to communicate properly due to mental illness or cognitive impairment.

\subsection{Research Method}

\subsubsection{Investigation Method}

The survey used a unified assessment form that included general information and stroke factors [17]. On-site questionnaires and physical examinations are conducted by qualified medical personnel who are trained and tested. The study was approved by the ethics committee and informed consent was obtained from the study subjects.

\subsubsection{Diagnostic Criteria}

Using the latest stroke risk screening assessment criteria by the Stroke Screening and Prevention Engineering Committee, high-risk stroke patients include a history of previous ischemic stroke or transient ischemic attack (TIA), or 3 of the following 8 risk factors Items and above: 1) Hypertension $(\geq 140 / 90 \mathrm{mmHg}, 1$ $\mathrm{mmHg}=0.133 \mathrm{kPa}$ ), or taking antihypertensive drugs; 2) Atrial fibrillation or valvular heart disease; 3 ) Smoking (evaluation criteria: $\geq 1$ cigarette/day, duration more than 1 year); 4) Dyslipidemia or unknown; 5) Diabetes; 6) Less physical exercise (evaluation criteria: $\geq 3$ times/week, $\geq 30$ minutes/time, duration more than 1 year; those who are engaged in moderate or severe physical labor are regarded as regular physical exercise); 7) Obesity (BMI $\geq 26 \mathrm{~kg} / \mathrm{m}^{2}$ ); 8) Family history of stroke. There were fewer than 3 risk factors of stroke, but with one of the chronic diseases (hypertension, diabetes, atrial fibrillation, or valvular heart disease) was assessed as a middle-risk group. The risk factors of stroke were less than 3 , and without chronic disease were assessed as a low-risk group.

\subsubsection{Quality Control}

All personnel involved in the stroke screening program must receive uniform training. During the development of the screening project, quality control personnel should be set up, all screening registration forms should be quality-controlled, and errors or missing items should be corrected in time to ensure the validity of the registration form. The data entry is double-checked and double entered to ensure the data is accurate.

\subsubsection{Statistical Method}

Data input and management were performed using Excel software, and data analysis was performed using SPSS 22.0 statistical software. Count data adoption 
rate and percentage description. Chi-square test was used to compare between groups. $P<0.05$ was considered statistically significant.

\section{Results}

\subsection{Basic Situation of the Research Object}

In this study, a total of 1060 subjects were screened. Finally, the data of 1060 patients were included in the study, and the effective rate was $100 \%$. The general demographic characteristics of the study population are shown in Table 1.

\subsection{Screening Result}

A total of 313 patients (29.53\%) with high-risk of stroke were identified, including 100 patients (31.95\%) with previous stroke and 56 patients $(17.89 \%)$ with transient ischemic attack (TIA).In the high-risk group, The exposure rate of risk factors from high to low was hypertension (70.93\%), dyslipidemia (46.33\%), less physical exercise $(46.01 \%)$, diabetes $(36.10 \%)$, overweight $(33.55 \%)$, smoking (33.23\%), family history of stroke $(24.92 \%)$, atrial fibrillation or valvular heart disease $(7.35 \%)$, as shown in Figure 1. Compared with the middle and low-risk groups, high-risk groups had statistically significant differences in hypertension, atrial fibrillation or valvular heart disease, smoking, dyslipidemia, diabetes, less physical exercise, overweight, and family history of stroke $(P<0.01)$, as shown in Table 2. There was a statistically significant difference in smoking between men and women $(P<0.05)$, as shown in Table 3.

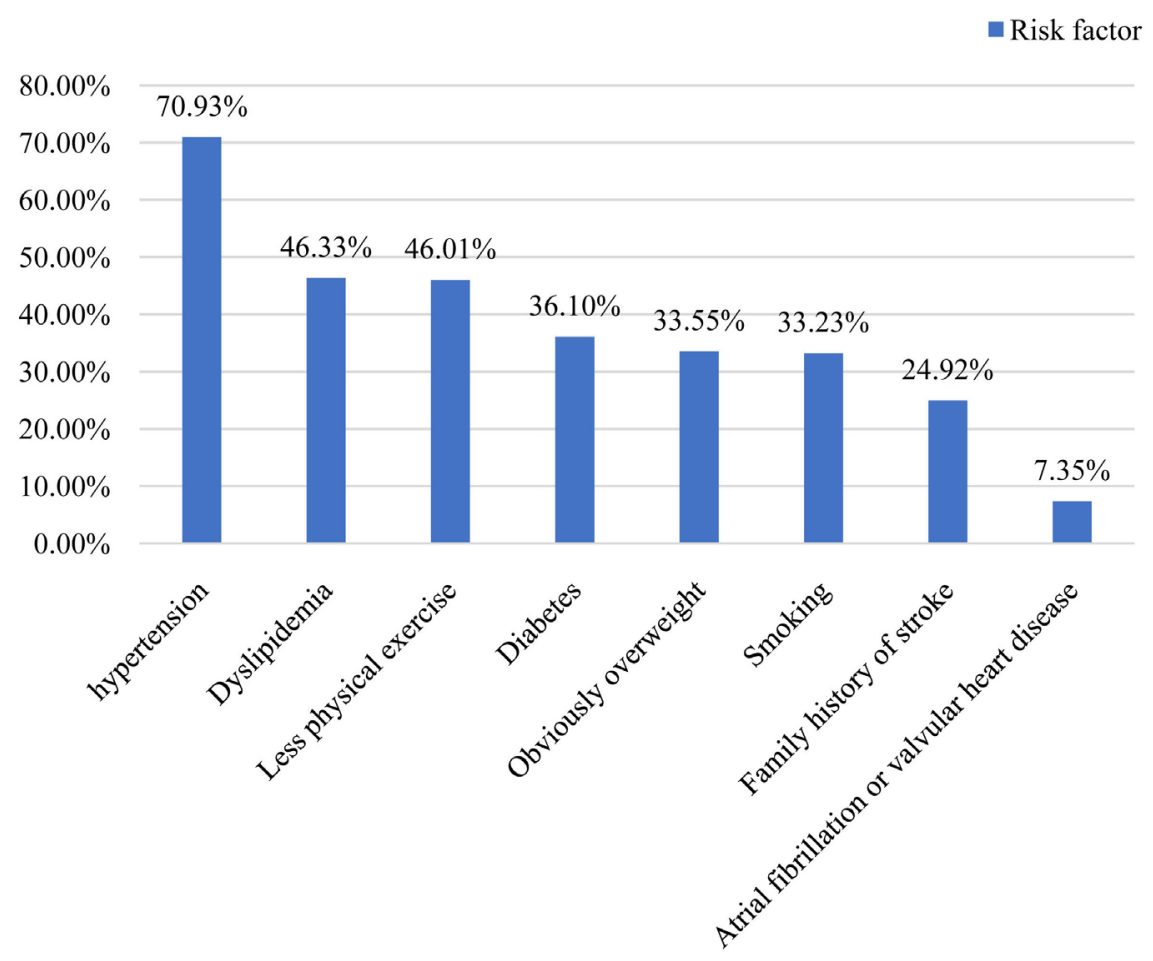

Figure 1. Distribution of risk factors in high-risk populations of stroke. 
Table 1. General demographic characteristics.

\begin{tabular}{|c|c|c|c|}
\hline Variable & Project & Frequency & Composition ratio (\%) \\
\hline \multirow[t]{2}{*}{ Gender } & Male & 484 & 45.7 \\
\hline & Female & 576 & 54.3 \\
\hline \multirow[t]{4}{*}{ Age } & $40 \sim$ & 223 & 21.0 \\
\hline & $51 \sim$ & 336 & 31.7 \\
\hline & $61 \sim$ & 342 & 32.3 \\
\hline & $71 \sim$ & 159 & 15.0 \\
\hline \multirow[t]{2}{*}{ Nationality } & Han nationality & 1045 & 98.6 \\
\hline & Minority & 15 & 1.4 \\
\hline \multirow[t]{3}{*}{ marriage } & Married & 920 & 86.8 \\
\hline & Widowed or divorced & 86 & 8.1 \\
\hline & Other & 54 & 5.1 \\
\hline \multirow[t]{3}{*}{ Career } & Farmer & 657 & 62.0 \\
\hline & Worker & 170 & 16.0 \\
\hline & Other & 233 & 22.0 \\
\hline \multirow[t]{3}{*}{ Educational level } & Elementary school and below & 657 & 62.0 \\
\hline & Junior high school & 300 & 28.3 \\
\hline & High school and above & 103 & 9.7 \\
\hline \multirow[t]{2}{*}{ Living situation } & Living alone & 58 & 5.5 \\
\hline & Non-independent & 1002 & 94.5 \\
\hline \multirow[t]{4}{*}{ Medical payment method } & Self-pay & 16 & 1.5 \\
\hline & Medical insurance & 872 & 82.3 \\
\hline & Other & 172 & 16.2 \\
\hline & $<1000$ & 234 & 22.1 \\
\hline \multirow{3}{*}{$\begin{array}{l}\text { Monthly per capita } \\
\text { income of the } \\
\text { family (yuan) }\end{array}$} & $1000-2000$ & 492 & 46.4 \\
\hline & $2000-3000$ & 234 & 22.1 \\
\hline & $>3000$ & 100 & 9.4 \\
\hline \multirow[t]{3}{*}{ Number of risk factors } & 3 & 65 & 20.8 \\
\hline & 4 & 46 & 14.7 \\
\hline & $\geq 5$ & 24 & 7.7 \\
\hline
\end{tabular}

Table 2. Statistical results of risk factors in high-risk group and middle and low-risk. groups of stroke [n (\%)].

\begin{tabular}{cccccccccc}
\hline Group & $\begin{array}{c}\text { Number } \\
\text { of cases }\end{array}$ & Hypertension & $\begin{array}{c}\text { Atrial } \\
\text { fibrillation or } \\
\text { valvular heart } \\
\text { disease }\end{array}$ & Smoking & Dyslipidemia & Diabetes & $\begin{array}{c}\text { Less } \\
\text { physical } \\
\text { exercise }\end{array}$ & $\begin{array}{c}\text { Family } \\
\text { Group }\end{array}$ & $\begin{array}{c}\text { history of } \\
\text { stroke }\end{array}$ \\
\hline High-risk group & 313 & $222(70.93)$ & $23(7.35)$ & $104(33.23)$ & $145(46.33)$ & $113(36.10)$ & $144(46.01)$ & $105(33.55)$ & $78(24.92)$ \\
$\begin{array}{c}\text { Middle and } \\
\text { low-risk group }\end{array}$ & 747 & $168(22.49)$ & $13(1.74)$ & $103(13.79)$ & $110(14.73)$ & $46(6.16)$ & $117(15.66)$ & $87(11.65)$ & $43(5.76)$ \\
$\chi^{2}$ & & 222.525 & 21.143 & 53.036 & 120.564 & 155.123 & 109.426 & 71.323 & 80.109 \\
$P$ & & $<0.001$ & $<0.001$ & $<0.001$ & $<0.001$ & $<0.001$ & $<0.001$ & $<0.001$ & $<0.001$ \\
\hline
\end{tabular}


Table 3. Stroke risk factors by gender statistics [n (\%)].

\begin{tabular}{|c|c|c|c|c|c|c|c|c|c|}
\hline Group & $\begin{array}{l}\text { Number } \\
\text { of cases }\end{array}$ & Hypertension & $\begin{array}{c}\text { Atrial } \\
\text { fibrillation or } \\
\text { valvular heart } \\
\text { disease }\end{array}$ & Smoking & Dyslipidemia & Diabetes & $\begin{array}{c}\text { Less } \\
\text { physical } \\
\text { exercise }\end{array}$ & $\begin{array}{l}\text { Obviously } \\
\text { overweight }\end{array}$ & $\begin{array}{c}\text { Family } \\
\text { history of } \\
\text { stroke }\end{array}$ \\
\hline Male & 484 & $195(40.29)$ & $17(3.51)$ & $184(38.02)$ & $120(24.79)$ & $76(15.70)$ & $133(27.48)$ & $98(20.25)$ & $53(10.95)$ \\
\hline Female & 576 & $195(33.85)$ & $19(3.30)$ & $23(3.99)$ & $135(23.44)$ & $83(14.41)$ & $128(22.22)$ & $94(16.32)$ & $68(11.81)$ \\
\hline$x^{2}$ & & 4.683 & 0.370 & 193.737 & 0.256 & 0.345 & 3.916 & 2.737 & 0.190 \\
\hline$P$ & & $>0.05$ & $>0.05$ & $<0.05$ & $>0.05$ & $>0.05$ & $>0.05$ & $>0.05$ & $>0.05$ \\
\hline
\end{tabular}

\section{Discussion}

The results of this study show that the detection rate of high-risk stroke population in this region was relatively high, accounting for $29.53 \%$, which was higher than the $15.32 \%$ of high-risk stroke population aged 40 and above reported by Yue [18]. In the high-risk group, the exposure rate of risk factors from high to low was hypertension $(70.93 \%)$, dyslipidemia $(46.33 \%)$, less physical exercise (46.01\%), diabetes $(36.10 \%)$, overweight (33.55\%), smoking (33.23\%), family history of stroke (24.92\%), atrial fibrillation or valvular heart disease (7.35\%), Among the 313 high-risk stroke patients, there were 65 patients with 3 risk factors (20.77\%), 46 patients with 4 risk factors (14.70\%), and 24 patients with more than 5 risk factors (7.67\%), it indicates that the stroke burden in this area is heavy. In addition, the risk factors of hypertension, dyslipidemia, less physical exercise, diabetes, overweight, smoking, family history of stroke, atrial fibrillation and valvular heart disease were statistically significant in the high-risk and middle and low-risk groups $(P<0.05)$. There is a statistically significant difference in smoking between men and women $(P<0.05)$.

Stroke is a multifactorial related disease, and its incidence trend is closely related to the exposure level of risk factors. Studies have shown that more than $80 \%$ of stroke cases can be controlled by improving people's unhealthy lifestyle and behaviors and strengthening self-health management [19] [20]. The results of this study found that the top three risk factors for high-risk stroke patients in this region were hypertension, dyslipidemia, and less physical exercise, which were controllable risk factors. Hypertension is the most important independent risk factor for stroke. $40 \%$ of cardiovascular and cerebrovascular diseases in China are attributed to hypertension. Among the many risk factors for stroke, hypertension is the first. With the increase of blood pressure, the risk of cardiovascular and cerebrovascular diseases increases gradually, and the risk of cardiovascular and cerebrovascular diseases increases by 1 time for every $20 \mathrm{mmHg}$ of systolic blood pressure or $10 \mathrm{mmHg}$ of diastolic blood pressure [21]. In a study by Goldstein [22], it is pointed out that maintaining proper exercise can reduce the incidence of stroke by $20 \%$, multiple exercise can reduce the incidence of stroke by $27 \%$, exercise can lower blood pressure, prevent atherosclerosis, and thus reduce the occurrence and recurrence of stroke. Some studies have 
shown that targeted interventions for high-risk stroke patients can also effectively reduce the incidence of stroke. In the study of Ai, et al. [23], standardized drug treatment for people with high-risk factors such as hypertension, diabetes and dyslipidemia can control blood pressure, blood sugar and blood lipids within the normal range, thereby reducing the incidence of stroke. In the study of $\mathrm{Li}$, et al. [24], targeted health education was conducted for cardiovascular patients with stroke risk factors, which mainly included early identification and control of stroke risk factors, guidance for patients to establish a good lifestyle to improve the knowledge of stroke prevention and treatment. Pan, et al. [25], through the implementation of health management interventions for high-risk stroke patients, strengthen self-health awareness and behavior to improve the clinical outcomes of high-risk stroke patients, and reduce the incidence of stroke. The high-risk factors of stroke in this area are mainly related to people's daily diet and behavior. It can improve people's health behavior compliance by strengthening health education and supervision, thus reducing the incidence and recurrence rate of stroke.

At present, although the prevention and treatment of stroke have made great progress, there are still some challenges. People' awareness of prevention and control, healthy lifestyles and risk factors are still not ideal. The knowledge of stroke prevention and treatment is generally lacking, and the compliance of healthy behaviors is not optimistic. Studies show that the awareness rate, treatment rate and control rate of hypertension in Chinese adults $\geq 18$ years old are $51.6 \%, 45.8 \%$ and $16.8 \%$ respectively [26]. The smoking rate among men is still at a high level, and the smoking rate of people aged $\geq 15$ years is $27.7 \%$ (52.1\% for men and $2.7 \%$ for women). The proportion of dyslipidemia in the population has increased significantly, the overall male is higher than the female, and the urban is higher than the rural [27]. Diabetes epidemiological survey showed that the national diabetes awareness rate was $36.50 \%$, the treatment rate was $32.20 \%$, and the treatment control rate was $49.20 \%$ [28]. The prevention and treatment of stroke is a long-term and arduous task that requires multidisciplinary cooperation, continuous supervision and management, thereby improving the health of all citizens.

\section{Conclusion}

The detection rate of high-risk stroke patients in Shashi District of Jingzhou City is high. Hypertension, dyslipidemia, less physical exercise, diabetes, and overweight are the main risk factors of stroke occurrence and recurrence in the region. The prevention and treatment of risk factors for stroke should be strengthened to control the incidence and recurrence rate of stroke.

\section{Acknowledgements}

This study was supported by Hubei Provincial Health and Health Commission research project (WJ2019F129). 


\section{Conflicts of Interest}

The authors declare no conflicts of interest regarding the publication of this paper.

\section{References}

[1] Zeng, Y.Z., X, X.L., Z, D.H., et al. (2016) The Effect of Health Education Intervention Based on Stroke Screening on the Prevention and Treatment of Stroke in Community Residents in Xiaogan City. Journal of Nursing, 23, 67-72.

[2] He, C.C. and Yang, W.L. (2017) Analysis of Screening Results of High-Risk Population in a Community in Nanchang City. Chinese Primary Health Care, 31, 41-43.

[3] Kim, A.S., Cahill, E. and Cheng, N.T. (2015) Global Stroke Belt: Geographic Variation in Stroke Burden Worldwide. Stroke, 46, 3564-3570.

https://doi.org/10.1161/STROKEAHA.115.008226

[4] Moran, A., Gu, D., Zhao, D., et al. (2010) Future Cardiovascular Disease in China: Markov Model and Risk Factor Scenario Projections from the Coronary Heart Disease Policy Model-China. Circulation: Cardiovascular Quality and Outcomes logo, 3, 243-252. https://doi.org/10.1161/CIRCOUTCOMES.109.910711

[5] Graham, I.M., Daly, L.E., Refsum, H.M., et al. (1997) Plasma Homocysteine as a Risk Factor for Vascular Disease. The European Conceded Action Project. The Journal of the American Medical Association, 277, 775-1781. https://doi.org/10.1001/jama.1997.03540460039030

[6] Meier, B., Frank, B., Wahl, A. and Diener, H.C. (2012) Secondary Stroke Prevention: Patent Foramen Ovale, Aortic Plaque, and Carotid Stenosis. European Heart Journal, 33, 705-713. https://doi.org/10.1093/eurheartj/ehr443

[7] Castilla-Guerra, L. and Fernandez-Moreno Mdel, C. (2012) Blood Pressure and Stroke Prevention among People with Cardiovascular Disease. Annals of Neurology, 72, 148-149. https://doi.org/10.1002/ana.23611

[8] Ciervo, C.A., Granger, C.B. and Schaller, F.A. (2012) Stroke Prevention in Patients with a Trial Fibrillation: Disease Burden and Unmet Medical Needs. The Journal of the American Osteopathic Association, 112, 2-8.

[9] Di Legge, S., Koch, G., Diomedi, M., Stanzione, P. and Sallustio, F. (2012) Stroke Prevention: Managing Modifiable Risk Factors. Stroke Research and Treatment, 2012, Article ID: 391538. https://doi.org/10.1155/2012/391538

[10] Wang, H.B., Li, Y.L., Wang, L.Q., et al. (2014) Status of Stroke and Influencing Factors in Residents Aged 40 Years or Older in Haidian District, Beijing. China Public Health, 30, 583-585.

[11] Zhong, D.Q., Jiang, X.J., Shen, Y.Y., et al. (2014) Establishment and Application of Standardized Screening Mode for High Risk Population of Stroke. Chongqing Medical Journal, 4, 1428-1430.

[12] Cao, C.L., Yu, N., Lin, X.J., et al. (2014) Risk Factors Associated with High-risk Population of Stroke. Journal of Clinical Neurology, 27, 335-337.

[13] Wu, C.L., Zhong, F.F., Zhang, Y.X. and Miao, X.Y. (2014) Analysis of Screening Results of High-Risk Population in Stroke. Chinese Journal of General Practice, 4, 549-553.

[14] Zhou, M., Wang, H., Zhu, J., et al. (2016) Cause-Specific Mortality for 240 Causes in China during 1990-2013: A Systematic Subnational Analysis for the Global Burden of Disease Study 2013. The Lancet, 387, 251-272. 
https://doi.org/10.1016/S0140-6736(15)00551-6

[15] O’Donnell, M.J., Chin, S.L., Rangarajan, S., et al. (2016) Global and Regional Effects of Potentially Modifiable Risk Factors Associated with Acute Stroke in 32 Countries (INTERSTROKE): A Case-Control Study. The Lancet, 388, 761-775. https://doi.org/10.1016/S0140-6736(16)30506-2

[16] Wang, L., Ren, H.C., Wang, Z.X., et al. (2018) Early Screening of Risk Factors of Stroke and Treatment of High-Risk Individuals. Journal of Brain and Nervous Diseases, 26, 212-215.

[17] National Health and Family Planning Commission Stroke Screening and Prevention Engineering Committee (2014) Technical Specifications for Stroke Screening and Prevention. Chinese Journal of Neurology, 47, 199-203.

[18] Yue, W. (2016) Investigation on the Prevalence of Stroke and Related Risk Factors among Chinese People Aged 40 and over. Tianjin Medical University, Tianjin.

[19] Shen, W.N., Nie, H.H. and Bao, Y. (2016) Investigation on Risk Factors of High-Risk Population in a Community in Shanghai. Chinese Journal of General Practice, 14, 996-998.

[20] Wu, Y.Z. and Chen, W.W. (2016) A Survey of Stroke in China. Journal of Cardiovascular and Cerebrovascular Diseases, 16, 410-414.

[21] Wang, W., Liu, M.B., Ma, L.Y., et al. (2017) The Effect of Prevention and Treatment of Hypertension in China and the Decline of Stroke Mortality. Chinese Journal of Cardiology, 22, 313-315.

[22] Goldstein, L.B., Adams, R., Alberts, M.J., et al. (2006) Primary Prevention of Ischemic Stroke: A Guideline from the American Heart Association/American Stroke Association Stroke Council: Cosponsored by the Atherosclerotic Peripheral Vascular Disease Interdisciplinary Working Group; Cardiovascular Nursing Council; Clinical Cardiology Council; Nutrition, Physical Activity, and Metabolism Council; and the Quality of Care and Outcomes Research Interdisciplinary Working Group. Stroke, 37, 1583-1633. https://doi.org/10.1161/01.STR.0000223048.70103.F1

[23] Ai, Y.T., Hu, H., Wang, L., Xu, Q. and Wu, Y. (2015) Analysis of Risk Factors and Management Status of Stroke among the Elderly in the Community. Journal of Nurses Training, 16, 1470-1472.

[24] Li, J., Li, H.L., Huang, W.J., et al. (2016) Primary Prevention Education for Stroke Patients with Cardiovascular Disease. Journal of Nursing Science, 31, 70-71.

[25] Pan, Q. and Wang, L.Q. (2017) Evaluation and Analysis of Health Management Effect in High-risk Groups of Stroke. Chinese Journal of Health Statistics, 34, 443-444.

[26] Wang, Z., Chen, Z., Zhang, L., et al. (2018) Status of Hypertension in China: Results from the China Hypertension Survey in 2012-2015. Circulation, 137, 2344-2356. https://doi.org/10.1161/CIRCULATIONAHA.117.032380

[27] Hu, S.S., Gao, R.L., Liu, L.S., et al. (2019) Summary of China Cardiovascular Disease Report 2018. Chinese Journal of Circulation, 34, 209-220.

[28] Wang, L., Gao, P., Zhang, M., et al. (2017) Prevalence and Ethnic Pattern of Diabetes and Prediabetes in China in 2013. The Journal of the American Medical Association, 317, 2515-2523. https://doi.org/10.1001/jama.2017.7596 